\title{
UJI PERFORMA PENGARUH IGNITION TIMING TERHADAP KINERJA MOTOR BENSIN BERBAHAN BAKAR LPG
}

\author{
Nana Supriyana \\ Program Studi Teknik Mesin \\ Sekolah Tinggi Teknik Wiworotomo Purwokerto \\ Email: Nana.sttw@gmail.com \\ Taufiq Hidayat \\ Fakultas Teknik, Program Studi Teknik Mesin \\ Universitas Muria Kudus \\ Email: ophiqhd@gmail.com
}

\begin{abstract}
ABSTRAK
Tujuan penelitian untuk mengetahui berapa besar pengaruh perubahan ignition timing terhadap performance motor bensin berbahan bakar LPG. Pada penelitian ini menggunakan motor bensin 4 langkah 1 silinder yang dilengkapi dengan konverter kits. Variabel bebas dalam penelitian adalah variasi ignition timing berbahan bakar LPG dengan sudut pengapian. Sedangkan variabel terikat adalah seberapa besar pengaruh variasi ignition timing berbahan bakar LPG terhadap torsi dan daya pada motor bensin. Pengujian dilakukan pada putaran 4250 - $8250 \mathrm{rpm}$ dengan menggunakan dynamometer inersia dan unjuk kerja yang dicari meliputi torsi dan daya. Dari hasil pengujian dapat disimpulkan bahwa performance torsi dan daya tertinggi yang dihasilkan motor bensin berbahan bakar LPG pada sudut pengapian $32^{\circ}$.
\end{abstract}

Kata kunci: ignition, LPG, motor bensin.

\begin{abstract}
The research objective to determine how much influence the ignition timing changes on performance gasoline motor fuel LPG. In this research use of motor gasoline 4-stroke 1-cylinder is equipped with a converter kits. The independent variable is the variation of LPG-fueled ignition timing with the ignition angle. The dependent variable is how much influence the variation of LPG-fueled ignition timing to the torque and power of the motor gasoline. Testing carried out on rotation 4250 - 8250 rpm using inertia dynamometer and performance searched include torque and power. From the test results it can be concluded that the performance of torque and peak power produced by gas LPG-fueled engine in the ignition angle of $32^{\circ}$.
\end{abstract}

Keywords: ignition, $L P G$, gasoline engine.

\section{PENDAHULUAN}

Perkembangan teknologi kendaraan bermotor sebagai salah satu alat transportasi, sangat memudahkan manusia dalam melaksanakan suatu pekerjaan, selain mempercepat dan mempermudah aktivitas, di sisi lain penggunaan kendaraan bermotor juga menimbulkan dampak yang sangat buruk terhadap lingkungan, terutama gas buang dari hasil pembakaran bahan bakar yang tidak terurai atau terbakar dengan sempurna.

Motor bensin 4 langkah merupakan suatu pesawat tenaga yang menghasilkan tenaganya dari proses pembakaran campuran bahan bakar bensin dan udara yang dilakukan dalam 4 langkah piston dalam silindernya [1]. Kinerja suatu motor ditunjukan dari beberapa hal yaitu daya yang dihasilkan , torsi yang dihasilkan, konsumsi bahan bakar, kandungan dalam sisa pembakaran/gas buang. Untuk mencapai kinerja motor yang baik suatu motor harus mempertimbangkan beberapa hal diantaranya adalah perbandingan kompresi, campuran bahan bakar dan udara, saat pengapian/pembakaran bahan bakar, nilai oktan yang terkandung dalam bahan bakar tersebut. Banyak hal yang telah dilakukan oleh praktisi maupun masyarakat pada umumnya untuk menghasilkan kinerja motor seperti menggunakan bahan bakar beroktan tinggi, menaikan perbandingan kompresi, menggunakan komponen system pengapian yang bagus dsb. 
Kendaraan bermotor yang menggunakan bahan bakar minyak (BBM) mengandung timah hitam (Leaded gasoline), dimana timah hitam ini selain untuk meningkatkan nilai oktan juga berpengaruh terhadap efek negatif [2]. Fenomena ini mendorong manusia untuk berusaha mencari pengganti bahan bakar minyak untuk mengoperasikan mesin. Salah satu jenis bahan bakar yang memungkinkan untuk menggantikan bahan bakar minyak pada kendaraan bermotor adalah bahan bakar Liquefied Petroleum Gas $(L P G)$.

Penggunaan $L P G$ sebagai bahan bakar pada motor bensin berkembang sangat baik. Selain murah, ramah lingkungan juga memiliki angka oktan yang lebih tinggi dibanding dengan bensin sehingga tenaga yang dihasilkan dari proses pembakaran dalam silinder lebih baik. Salah satu cara untuk meningkatkan unjuk kerja dari motor bensin yang menggunakan bahan bakar gas adalah dengan mengatur ignation timing sehingga waktu pengapiannya menjadi lebih tepat. Tujuan dari penelitian ini untuk mengetahui pengaruh perubahan ignation timing terhadap unjuk kerja sepeda motor berbahan bakar $L P G$.

Beberapa penelitian terdahulu yang dilakukan antara lain Bambang Yunianto [3], meneliti pengaruh perubahan saat penyalaan (ignition timing) terhadap prestasi mesin pada sepeda motor 4 langkah dengan bahan bakar $L P G$. Hasil performa untuk dua jenis bahan bakar yaitu bensin dan $L P G$ dengan pengubahan pada sudut pengapian, diperoleh data bahwa pemakaian bahan bakar $L P G$ menghasilkan daya dan torsi rata-rata sebesar $25 \%$ lebih kecil dibandingkan daya dan torsi yang dihasilkan oleh bensin. Torsi dengan bahan bakar $L P G$ pada sudut pengapian $11^{\circ}$ lebih tinggi dari torsi pada variasi sudut pengapian yang lain, yaitu pada $4000 \mathrm{rpm}$ dengan torsi $8.309 \mathrm{Nm}$. Dibandingkan dengan bahan bakar bensin pengapian standart, $L P G 11^{\circ}$ hanya berselisih rata-rata $3 \%$ lebih kecil dari torsi bensin standart. Kondisi operasi terbaik mesin baik dengan bahan bakar bensin maupun $L P G$ dalam kisaran putaran 4.000 rpm sampai $5.000 \mathrm{rpm}$. Serta Atok Setiyawan[3], dalam penelitianya merubah ignition timing dan meningkatkan compression ratio menghasilkan unjuk kerja motor bensin berbahan bakar E-85 bila dibandingkan dengan kondisi standar, meskipun masih dibawah unjuk kerja premium. Ignition timing terbaik dicapai pada $30^{\circ}$ $B T D C$ sedangkan compressio ratio tercapai pada kondisi maksimum, yaitu 10,2:1. Berdasarkan variasi ignition timing dan compression ratio yang diteliti, hasil peneletian menunjukkan bahwa menentukan igntion timing yang tepat dapat memberikan perbaikan unjuk kerja motor bensin secara signifikan dibandingkan dengan compression ratio.

Dari uraian diatas dapat disimpulkan bahwa dengan mengatur sudut pengapian dapat meningkatkan performance engine berbahan bakar $L P G$, berdasarkan hasil penelitian terdahulu penulis melakukan penelitian lanjutan optimalisasi unjuk kerja dengan perubahan sudut pengapian $30^{\circ}, 32^{\circ}$ dan $34^{\circ}$ pada motor bensin berbahan bakar $L P G$.

\section{METODOLOGI}

\subsection{Desain Penelitian}

Desain penelitian yang digunakan adalah eksperimental. Penelitian ini membandingkan variasi ignation timing berbahan bakar $L P G$ pada motor bensin 4 langkah silinder 1 yang dipasang pada sepeda motor sebagai objek penelitian dengan menekankan pada unjuk kerja motor meliputi torsi dan daya menggunakan alat ukur Inertia Dynamometer.

\subsection{Variabel Penelitian}

\subsubsection{Variabel Bebas}

Variabel bebas adalah kondisi yang mempengaruhi munculnya suatu gejala. Dalam hal ini dapat dikatakan bahwa variabel bebas merupakan variabel yang sengaja dipelajari pengaruhnya terhadap variabel terikat. Variabel bebas pada penelitian ini adalah variasi ignation timing berbahan bakar $L P G$ dengan sudut pengapian.

\subsubsection{Variabel Terikat}

Variabel terikat adalah segala bentuk peristiwa atau gejala yang muncul sehubungan dengan pelaksanaan penelitian. Variabel terikat dari penelitian ini adalah seberapa besar pengaruh variasi ignation timing berbahan bakar $L P G$ motor bensin terhadap torsi dan daya pada sepeda motor 4 langkah 1 silinder. 


\subsubsection{Variabel Kontrol}

Variabel kontrol adalah himpunan sejumlah gejala yang memiliki berbagai aspek atau unsur didalamnya yang berfungsi untuk mengendalikan agar variabel terikat yang muncul bukan karena variabel lain, tetapi karena variabel bebas. Variabel kontrol dari penelitian ini adalah putaran mesin dari $4250,4500,4750,5000,5250,5500,5750,6000,6250,6500,6750,7000,7250,7500,7750,8000,8250$ rpm.

\subsection{Alat Dan Bahan}

\subsubsection{Alat Penelitian}

1. Tool set kunci

Digunakan sebagai alat untuk melepas dan memasang komponen motor yang dipakai dalam pengujian.

2. Dynamometer

Dynamometer yang digunakan adalah jenis dinamometer sasis, dipakai untuk mengukur output daya roda belakang. Data yang ditampilkan berupa grafik tenaga dan torsi mesin. Variasi tenaga dapat diatur terhadap waktu, kecepatan, dan putaran mesin.

\subsubsection{Bahan Penelitian}

1. Satu unit motor bensin dengan spesifikasi sebagi berikut :
a. Diameter x Langkah
: $51.0 \times 54.0 \mathrm{~mm}$
b. Voume Silinder
$: 110,3 \mathrm{CC}$
c. Perbandingan Kompresi
$: 9.3: 1$
d. Power Max
: 8,8 HP pada putaran $8000 \mathrm{rpm}$
e. Sistem Starter
: Motor starter dan starter engkol
f. Sistem Pelumasan
: Pelumasan Basah
g. Tipe Transmisi
h. Sistem Pengapian
: Tipe ROTARY 4 kecepatan
: DC CDI Programable

2. Bahan bakar LPG.

3. Regulator tekanan tinggi (high pressure).

\subsubsection{Prosedur Penelitian}

1. Persiapan eksperimen meliputi :

a. Menyiapkan dan memeriksa peralatan yang akan digunakan dalam penelitian.

b. Menyiapkan mesin yang akan digunakan untuk penelitian.

2. Pelaksanaan eksperimen

a. Mengukur unjuk kerja meliputi torsi dan daya dengan bahan bakar $L P G$ dengan sudut pengapian standart. Pengukuran putaran pada ban belakang mulai dari 4250, 4500, 4750, $5000,5250,5500,5750,6000,6250,6500,6750,7000,7250,7500,7750,8000,8250$ pada dynamometer dan komputer mensimulasikan beban dan membaca torsi, daya, yang disalurkan ban belakang pada roller drum.

b. Mengukur unjuk kerja meliputi torsi dan daya untuk mesin dengan bahan bakar $L P G$ dengan variasi sudut pengapian $30^{\circ}$ Setelah mesin dihidupkan, atur putaran mulai dari $4250,4500,4750,5000,5250,5500,5750,6000,6250,6500,6750,7000,7250,7500$, 7750, 8000, $8250 \mathrm{rpm}$.

c. Mengukur unjuk kerja meliputi torsi dan daya untuk mesin dengan bahan bakar $L P G$ dengan variasi sudut pengapian $32^{\circ}$ Setelah mesin dihidupkan, atur putaran mulai dari $4250,4500,4750,5000,5250,5500,5750,6000,6250,6500,6750,7000,7250,7500$, $7750,8000,8250 \mathrm{rpm}$.

d. Mengukur unjuk kerja meliputi torsi dan daya untuk mesin dengan bahan bakar $L P G$ dengan variasi sudut pengapian $34^{\circ}$ Setelah mesin dihidupkan, atur putaran mulai dari $4250,4500,4750,5000,5250,5500,5750,6000,6250,6500,6750,7000,7250,7500$, 7750, 8000, 8250 rpm. 


\section{HASIL DAN PEMBAHASAN}

\subsection{Data Hubungan Putaran Dengan Torsi}

Berdasarkan hasil penelitian yang dilakukan, didapat mengenai hubungan antara putaran dengan torsi. Data tersebut meliputi hubungan antara putaran dengan torsi baik pada kondisi pengapian standar, maupun yang sudah di modifikasi dengan sudut pengapian $30^{\circ}, 32^{\circ}$, dan $34^{\circ}$ dengan menggunakan bahan bakar $L P G$. Penelitian ini dilakukan pada putaran $4250 \mathrm{rpm}$ sampai $8250 \mathrm{rpm}$ dengan interval $250 \mathrm{rpm}$. Dasar pengambilan putaraan tersebut diambil mulai dari putaran minimal $4250 \mathrm{rpm}$. Setelah dilakukan penelitian didapat data seperti Gambar 1.

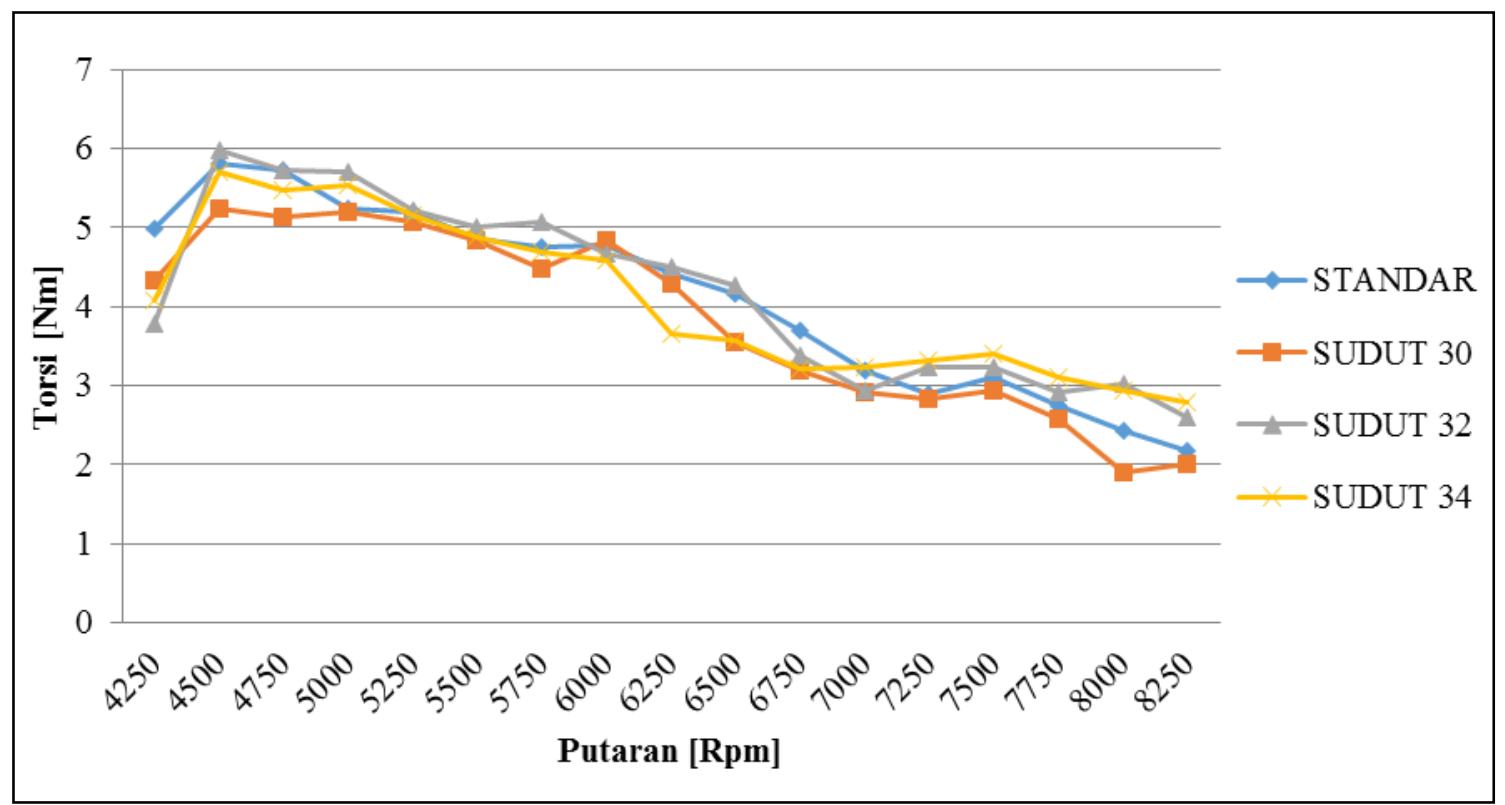

Gambar 1. Grafik Hubungan Torsi Dengan Putaran

Hasil dari uji eksperimen ditunjukan pada Gambar 1, terjadi perubahan torsi terhadap sudut pengapian standar menggunakan bahan bakar LPG. Perubahan sudut pengapian $30^{\circ}$ ke sudut pengapian $32^{\circ}$ menghasilkan peningkatan torsi sebesar $20,34 \%$, dari sudut pengapian $30^{\circ}$ ke sudut pengapian $34^{\circ}$ menghasilkan peningkatan torsi $22,74 \%$. Hasil torsi tertinggi untuk masing-masing sudut pengapian adalah sudut pengapian $30^{\circ}$ torsi tertinggi $5,23 \mathrm{Nm}$ pada $4500 \mathrm{rpm}$, untuk sudut pengapian $32^{\circ}$ torsi tertinggi $5,97 \mathrm{Nm}$ pada $4500 \mathrm{rpm}$, sedangkan untuk sudut pengapian $34^{\circ}$ didapat torsi tertinggi 6,01 Nm pada 4700 rpm.

Hasil torsi yang diperoleh pada penelitian yang menggunakan bahan bakar $L P G$ dengan sudut pengapian standar, $30^{\circ}, 32^{\circ}$, dan $34^{\circ}$ sebelum TMA didapat kenaikan pada putaran $6750-8250 \mathrm{rpm}$, hal ini disebabkan karena kecepatan perambatan nyala (flame velocity) LPG terbakar lebih cepat dari bensin pada kondisi $\lambda>1$, sehingga mengakibatkan pergeseran terjadinya tekanan puncak pembakaran, dengan memajukan sudut pengapian akan terlihat peningkatan yang terjadi pada performance motor bensin berbahan bakar $L P G$.

\subsection{Data Hubungan Putaran Dengan Daya}

Berdasarkan hasil penelitian yang dilakukan, didapat juga data hubungan antara putaran dengan daya motor. Data tersebut meliputi hubungan antara putaran dengan daya baik pada kondisi pengapian standar maupun yang sudah di modifikasi dengan sudut pengapian $30^{\circ}, 32^{\circ}$ serta $34^{\circ}$ menggunakan bahan bakar $L P G$ pada putaran 4250 - $8250 \mathrm{rpm}$ dengan interval $250 \mathrm{rpm}$. Pada Gambar 2 terlihat garfik hubungan putaran dan daya motor. 


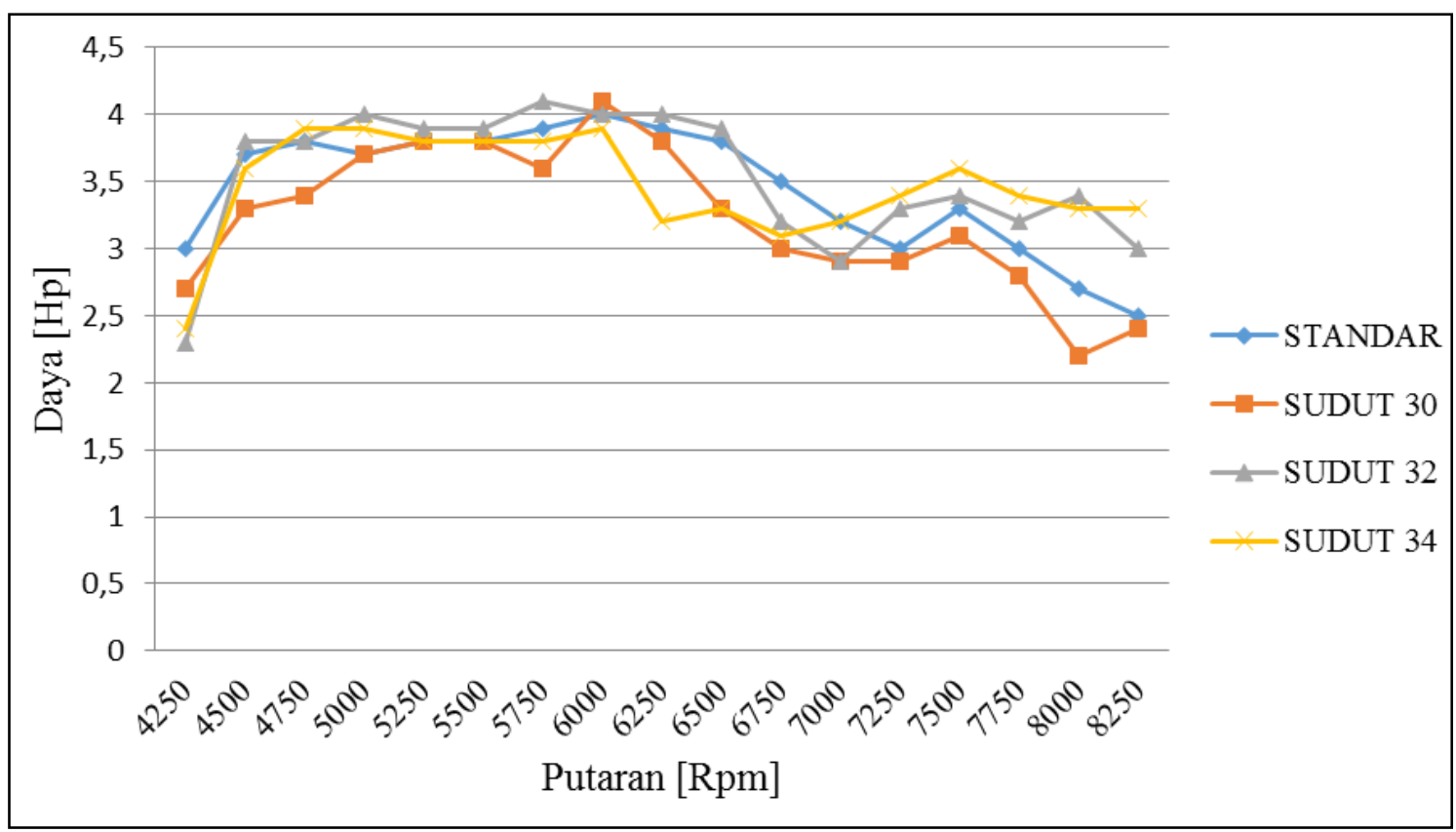

Gambar 2. Grafik Hubungan Daya Dengan Putaran

Berdasarkan Gambar 2. grafik hubungan daya dengan putaran menunjukan bahwa daya yang dihasilkan $L P G$ untuk sudut pengapian standar menghasilkan daya tertinggi 4,0 Hp pada putaran 6000 rpm dan yang terendah sebesar $2,5 \mathrm{Hp}$ pada $8250 \mathrm{rpm}$. Sedangkan untuk sudut pengapian $30^{\circ}$ daya tertinggi sebesar 4,1 Hp pada $6000 \mathrm{rpm}$ dan daya yang terendah 2,2 $\mathrm{Hp}$ pada $8000 \mathrm{rpm}$, kemudian sudut pengapian $32^{\circ}$ menghasilkan daya tertinggi sebesar 4,1 pada $5750 \mathrm{rpm}$ dan yang terendah 2,3 pada 4250 rpm. Sedangkan untuk sudut pengapian $34^{\circ}$ daya tertinggi didapat 4,0 Hp pada $4700 \mathrm{rpm}$ dan yang terendah 2,4 Hp pada $4250 \mathrm{rpm}$.

Perubahan kenaikan daya didapat para penerapan sudut pengapian $34^{\circ}$ hampir berada disemua putaran hasil ini disebabkan karena kecepatan perambatan nyala (flame velocity) LPG terbakar lebih cepat dari bensin pada kondisi $\lambda>1$. Hal ini akan mengakibatkan pergeseran terjadinya tekanan puncak pembakaran. Selain hal tersebut juga disebabkan karena LPG memiliki nilai oktan sebesar 112, nilai tesebut jauh lebih tinggi dibanding dengan bahan bakar bensin.

\section{KESIMPULAN}

Berdasarkan hasil penelitian dan analisa data tentang pengaruh perubahan ignation timing terhadap unjuk kerja sepeda motor berbahan bakar $L P G$ dapat diambil kesimpulan sebagai berikut:

1) Berdasarkan data hasil pengujian torsi tertinggi diperoleh pada sudut pengapian $32^{\circ}$ sebesar 5,97 Nm pada putaran $4500 \mathrm{rpm}$ dengan bahan bakar $L P G$.

2) Untuk hasil pengujian daya tertinggi diperoleh pada sudut pengapian $30^{\circ}$ sebesar $4,1 \mathrm{Hp}$ pada putaran $6000 \mathrm{rpm}$ dan $32^{\circ}$ sebesar $4,1 \mathrm{Hp}$ pada putaran $5750 \mathrm{rpm}$.

\section{UCAPAN TERIMA KASIH}

Aprin kristianto dkk, yang telah mengambil tema peningkatan performa motor bensin sebagai tema dalam skripsi pada Program Studi Teknik Mesin STT Wiworotomo Purwokerto. Suwarso dkk, yang telah membantu pelaksanaan penelitian di laboratorium Teknik Mesin STT Wiworotomo Purwokerto maupun membantu komunikasi dengan laboran Universitas Muria Kudus.

\section{DAFTAR PUSTAKA}

[1] Aris Munandar, 1990. Motor Bakar Torak. Jakarta. PT.GRAMEDIA INDONESIA

[2] KSME International Journal, VoL 16 No. 7, pp. 935 941, 2002 Analysis of Combustion and Flame Propagation Characteristics of LPG and Gasoline Fuels by Laser Deflection Method 
[3] Atok Setiyawan, Pengaruh Ignition Timing Dan Compression Ratio Terhadap Unjuk Kerja Dan Emisi Gas Buang Motor Bensin Berbahan Bakar Campuran Etanol 85\% Dan Premium 15\% (E-85). Jurusan Teknik Mesin, Fakultas Teknologi Industri Its.

[4] Bambang Yunianto (2009), “ pengaruh perubahan saat penyalaan (ignition timing) terhadap prestasi mesin pada sepeda motor 4 langkah dengan bahan bakar lpg ”. Jurusan Teknik Mesin Fakultas Teknik Universitas Diponegoro Kampus Undip Tembalang, Semarang 50275, Indonesia. 